\title{
TESTING OF THE SUPERCONDUCTING SOLENOID
}

FOR THE FERMILAB COLLIDER DETECTOR*

R. W. Fast, C. N. Holmes, R. D. Kephart, J. B. Stoffel, M. E. Stone, R. H. Wands, and T. N. Zimmerman

Fermi National Accelerator Laboratory, Batavia, IL USA

and

K. Kondo, S. Mori, and R. Yoshizaki

University of Tsukuba, Sakura, Ibaraki, Japan

and

K. Asano

Hitachi Works, Hitachi, Ltd., Hitachi, Ibaraki, Japan

July 1985

* Submitted to Advances in Cryogenic Engineering, Vol. 31., and to be presented at the 1985 Cryogenic Engineering Conference, Cambridge, Massachusetts, September 13, 1985. 

R. W. Fast, C. N. Holmes, R. D. Kephart, J. B. Stoffel, M. E. Stone, R. H. Wands, and T. N. ZImmerman

Fermi National Accelerator Laboratory

Batavia, Illinols

K. Kondo, S. Mori, and R. Yosh1zaki

University of Tsukuba

Sakura, Ibarak1, Japan

K. Asano

Hitachi Works, Hitachi, Ltd. Hitach1, Ibarak1, Japan

\section{ABSTRACT}

The $3 \mathrm{~m} \phi \times 5 \mathrm{~m}$ long $\times 1.5 \mathrm{~T}$ superconducting solenoid for the Fermilab Collider Detector has been installed at Fermilab and was tested in early 1985 with a dedicated refrigeration system. The refrigerator and $5.6 \mathrm{Mg}$ magnet cold mass were cooled to $5 \mathrm{~K}$ in 210 hours. After testing at low currents, the magnet was charged to the design current of $5 \mathrm{kA}$ in 5-MJ steps. During a $390 \mathrm{~A} / \mathrm{min}$ charge a spontaneous quench occurred at $4.5 \mathrm{kA}$ due to insufficient liquid hellum flow. Three other quenches occurred during "slow" discharges which were nevertheless fast enough to cause high eddy current heating in the outer support cylinder. Quench behavior is well understood and the magnet is now quite rellable.

\section{INTRODUCTION}

The Fermllab Collider Detector utilizes a superconducting solenoid $3 \mathrm{~m} \phi 5 \mathrm{~m}$ to produce a horizontal magnetic fleld of $1.5 \mathrm{~T}$, to study $\bar{p}$ collisions in the Tevatron. To minimize measurement errors for particles passing through the solenoid it is fabricated largely of aluminum and 18 conduction cooled.

Design details of the CDF solenoid have been presented elsewhere.1 The single-layer coll uses an aluminum-stabilized conductor at an operating current of $5 \mathrm{kA}$. The cutward radial force is reacted in an aluminum outer support cylinder. The net forces on the co11/support cylinder are carried by Inconel supports. The coll is refrigerated by a flow of twophase helium at $\sim 5 \mathrm{~K}$ through an aluminum tube welded to the outer support cylinder. The vacuum vessel, fabricated of aluminum, is attached to an Iron flux return yoke. ${ }^{2}$ A control dewar, located above the cryostat and 
outside the Iron yoke, serves as the Interface between the magnet cryostat and the refrigeration system. The fabrication of the co11, cryostat and control dewar and the initial test without iron have been described earlier. $3^{-5}$

The refrigeration system ${ }^{6}$ is based upon the standard Fermtlab "satell1te" refrigerator wh1ch has a nominal capacity of $625 \mathrm{~W}$ or $125 \mathrm{~L} / \mathrm{h}$. Hellum of high liquid fraction is clrculated through the coll cooling tube using the main compressor to provide the required pressure differential. Two transfer lines permit operation of the magnet in either the Assembly Hall for testing or in the Collision Hall for the experiments. The refrigerator is computer controlled using the same hardware and ooftware as the Tevatron refrigerators. The refrigeration system was tested prior to magnet installation and was found to exceed 1 ts nominal capacity.

\section{DESCRIPTION OF BLBCTRICAL SYSTEM}

A schematic of the de circuit is shown In Fig. 1. The protection and Interlock system can Initlate a slow dump by opening Swl or a fast dump by opening SW2/SW3. The quench detection circuit uses the voltage taps V3 to v7 to detect normal reglons in the coll. A data logger bullt around Lecroy transient recorders and an IBM PC was used to accumulate steady state and.charge/discharge data during the cooldown and test. The electrical system is described in more detall elsewhere. 7

\section{COMMISSIONING OF MAGNET-REFRIGERATOR SYSTEM}

Assembly of Magnet at Fermilab

It was determined that the safest way to ship the magnet cryostatcontrol dewar from the Japanese vendor to Fermilab was by alr from Tokyo to Chicago. Heavylift Cargo Airlines, London, England, was chosen for the move since they operate the "Belfast," a large plane originally designed for milltary cargo use. It was necessary to separate the control dewar from the magnet cryostat by cutting the chimney vacuum shell and internal fluid lines about $300 \mathrm{~mm}$ from the cryostat. The cryostat and control dewar arrived at Fermilab on July 20, 1984. When the assembly of the Iron yoke was completed the cryostat and control dewar were installed and rejoined.

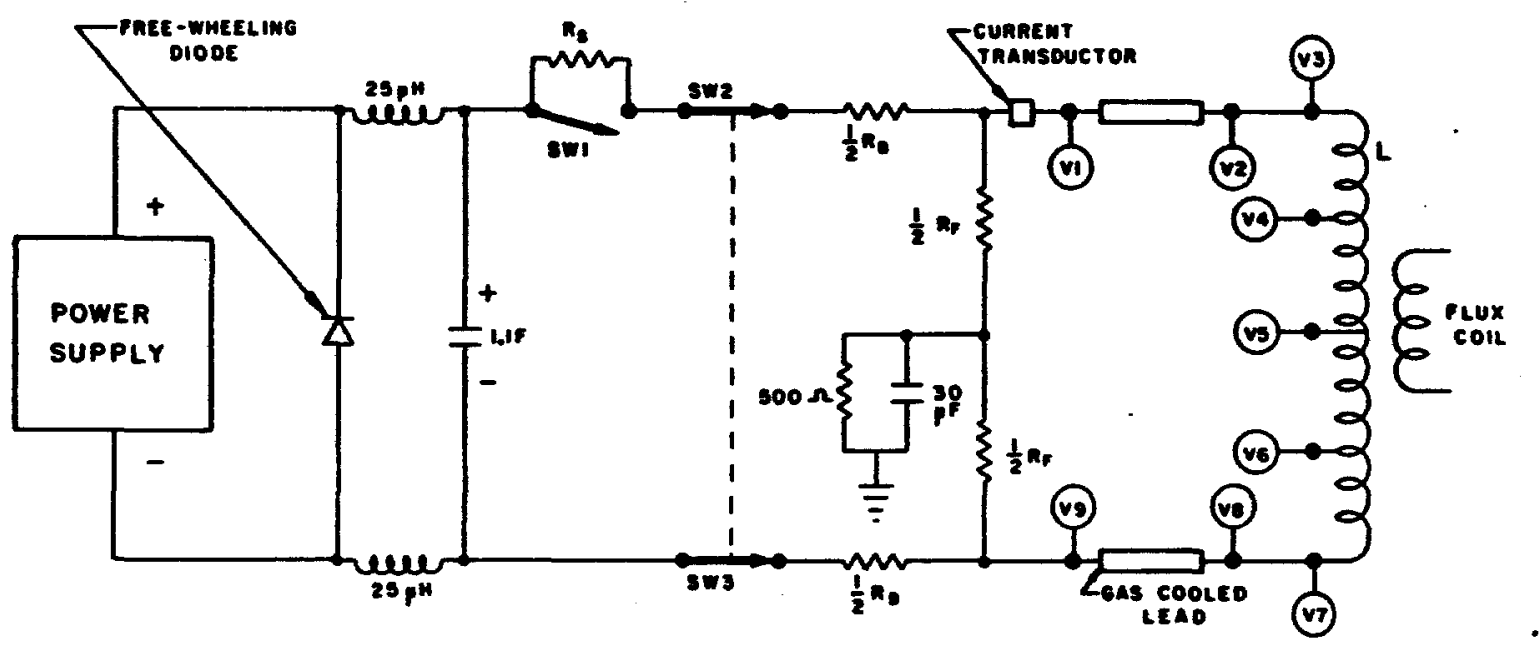

$L=2.4 \mathrm{H} \quad R_{g}=4 \mathrm{~m} \Omega \quad R_{\theta}=1.2 \mathrm{~m} \Omega \quad R_{f}=76 \mathrm{~m} \Omega$

F1g. 1. de circult of CDF solenold. 
In order to 1nsure that Fermllab employees are protected against the hazards pecullar to cryosystems, Permilab pollcy requires that ouch 8y8tems be designed in accordance with written otandards and analyzed for cryogenic safety. This pollcy also requires that the design and safety analysis be reviewed by an independent panel of cryogenic engineers and sclent18t8. The CDP magnet and refrigeration system was designed, safety analyzed, and reviewed in accordance with these requirements.

Hazards of liquid nitrogen and 11quid hellum systems. The general hazards associated with cryogenic systems have been treated elsewhere. 8 The primary hazards of the nitrogen-hellum cryosystens found at Fermilab are liquid cryogen spray and oxygen deficlency both of which can result from cryogen contalnment failure. At many of the Fermilab Installations these hazards are exacerbated by the location of major system components, e.g. superconducting magnets and 11quid transfer 11nes, in underground tunnels or in below-grade or underground experimental halls. The standard for evaluating the oxygen deficlency hazard (ODH) associated with cryogenic installations is given in the Fermilab Safety Manual. :

Design of vessels and piping. The Fermilab Safety Manual requires that cryogentc vessels and plping be designed and fabricated in accordance with Section VIII of the ASIE Boller and Pressure Vessel Code and Section B31 of the ASME Code for Pressure Piping. For example, the 11quid vessels of the CDF hellum and nitrogen storage dewars are Code stamped. Accepted practice at Fermilab for the vacuum vessels of dewars follows common Industrial practice, 1.e. a collapse pressure of $0.21 \mathrm{MPa}$ (30 p8i). Since the pressure in a cryogenic vessel must not exceed $110 \%$ of the pressure rating during relleving, qualitative calculations of the pressure rise in the rellef systems were performed. The fallure modes for which the rellef systems assoclated with the CDF magnet-refrigerator were analyzed are given in Table 1. The rellef devices on the hellum system are shown in F1g. 2 with detalls given in Table 2.

Table 1. Failure Modes Analyzed for CDF Cryogenlc Vessels

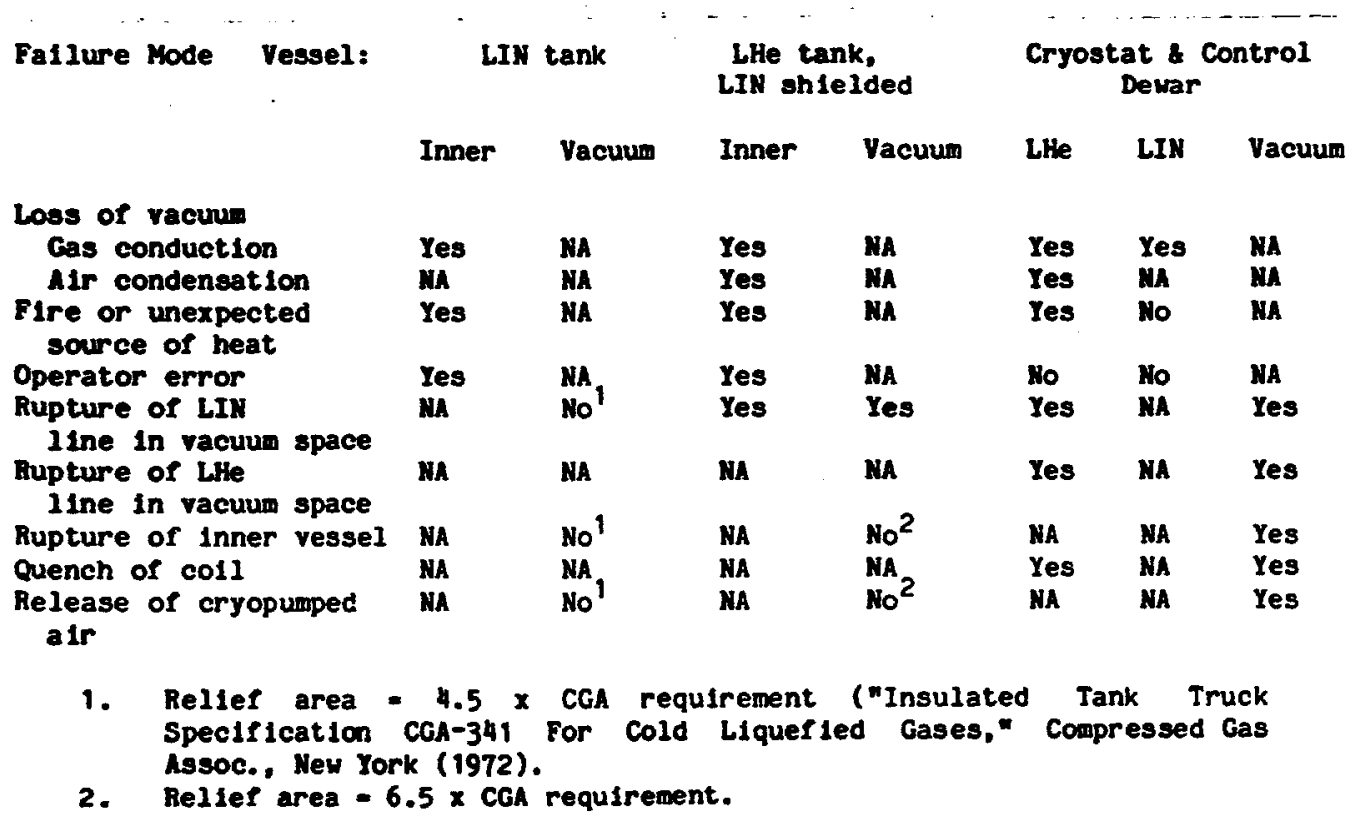




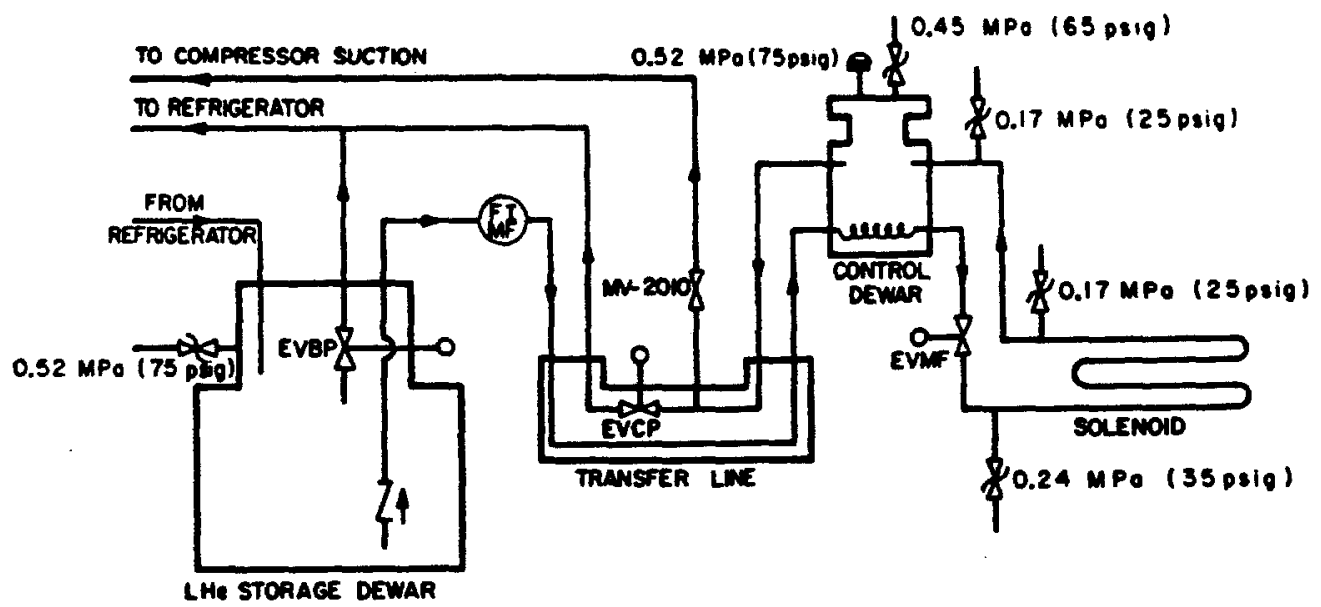

Fig. 2. Hellum system flow schematic.

- Assembly Hall ventilation and ODH analysis. The ventilation system required to prevent an $\mathrm{ODH}$ in an enclosed area may be sized by equating the mass flow rate of lnerting fluid into the building to the capacity of the ventilation system to remove 1t. In the CDF Assembly Hall an ODH assoclated with liquid nitrogen is prevented through use of a fan with a capacity of $3.8 \mathrm{~m}^{3} / \mathrm{s}$ which has an inlet at the lowest level of the hall and an outdoor discharge. The fan is controlled by an oxygen monitor at the $10 \mathrm{w}$ level. The hellum $\mathrm{ODH}$ is alleviated with roof louvers actuated by an oxygen monitor near the celling.

Table 2. Rellef Systems for CDF Cryogenic Vessels.

Vessel/PIping

LIH Tank

Inner ressel

Inner ressel

Vacuua ressel

He Tank

Inner ressel Acco

Inner vessel Fike

Vacuun ressel

-

Cryostat and Control Dewar

He ressel \& plping

He ressel piping

He ressel a piping

He ressel a piping

He reasel piping

Vacuum vessel

\begin{tabular}{l} 
AGCO \\
AGCO \\
Acco \\
Circle sea ${ }^{3}$ \\
Fike \\
\hline
\end{tabular}

rellef valve rellef valve reller vaive reller valve burst disk parallel plate
Setting

IPa (po1g)

$0.34(50)$

$0.40(58)$

$0.002(0.25)$

$0.52(75)$

$0.66(95)$

$0.002(0.25)$

345 (731)

464 (984)

$156(330)$

1. Inderson, Greenwood $\mathrm{CO}$., Bellaire, TX.

2. Fike Hetal Products Corp;, Blue Springs; 10.

3. Circle seal Corp.. Inaheia, CA. 
Cooldown procedure. The hellum circult for the magnet-refr1gerator 18 shown In Fig. 2. During cooldown, flow from the refrigerator passed through the storage dewar, transfer line and agget cooling circult and back through the return alde of the transfer 11ne. The electrically operated valve EVCP and the manual valve $\mathrm{MV}-2010$ were used to create an imbalance by returning a portion of the flow directly to compressor suction. The pressure in the storage dewar was maintained at 0.17-0.21 LPa (25-30 p81g) by the computer control system, wh1ch sensed dewar pressure and regulated EVBP. The control dewar pressure varled with the positions of EVCP and MV-2010, but ranged between 0.04 and $0.08 \mathrm{MPa}(6-12$ p81g).

The temperature of the coll/outer support cylinder was monitored with platinum and carbon resistors mounted on the support cylinder at several locations. The temperatures of the supply and return hellum flows were measured with simflar resistors in the piping.

Cooldown. Cooldown began on the morning of February 28, 1985, when 1iquid nitrogen flow was started to the precooling heat exchanger of the refrigerator.. A total compressor flow of $-40 \mathrm{~g} / \mathrm{s}$ was established. The hellum flow through the magnet cooling loop was measured by the venturi flowmeter FIMP as $\sim 5 \mathrm{~g} / \mathrm{s}$. Control valves on the liquid nitrogen shield and Intercept circuits were placed under computer control to regulate at $180 \mathrm{~K}$ as measured by platinum resistors. The maximum valve positions were limited to keep the cooling rates low. As cooldown progressed these set temperatures were lowered and the valves allowed to operate over a wider range unt1l full computer control was achleved at the operational set points of $90 \mathrm{~K}$ and $80 \mathrm{~K}$ for the shield and intercepts, respectively.

The coll reached a temperature of $97 \mathrm{~K}$ in 144 hours, at which time the gas expansion engine was started. FIMP Indicated a flow of approximately $8 \mathrm{~g} / \mathrm{s}$ through the magnet at this point. Twenty-four hours later, at a coll temperature of $72 \mathrm{~K}$, the liquid expansion engine was started. The coll resistance, which was contimuously monitored during the cooldown, Indicated that the coil became superconducting approximately 205 hours into cooldown. The operating temperature was reached 5 hours later. The average cooldown rate was $1.5 \mathrm{~K} / \mathrm{h}$. Figure 3 shows the measured coll $\therefore$ temperature as a function of time.

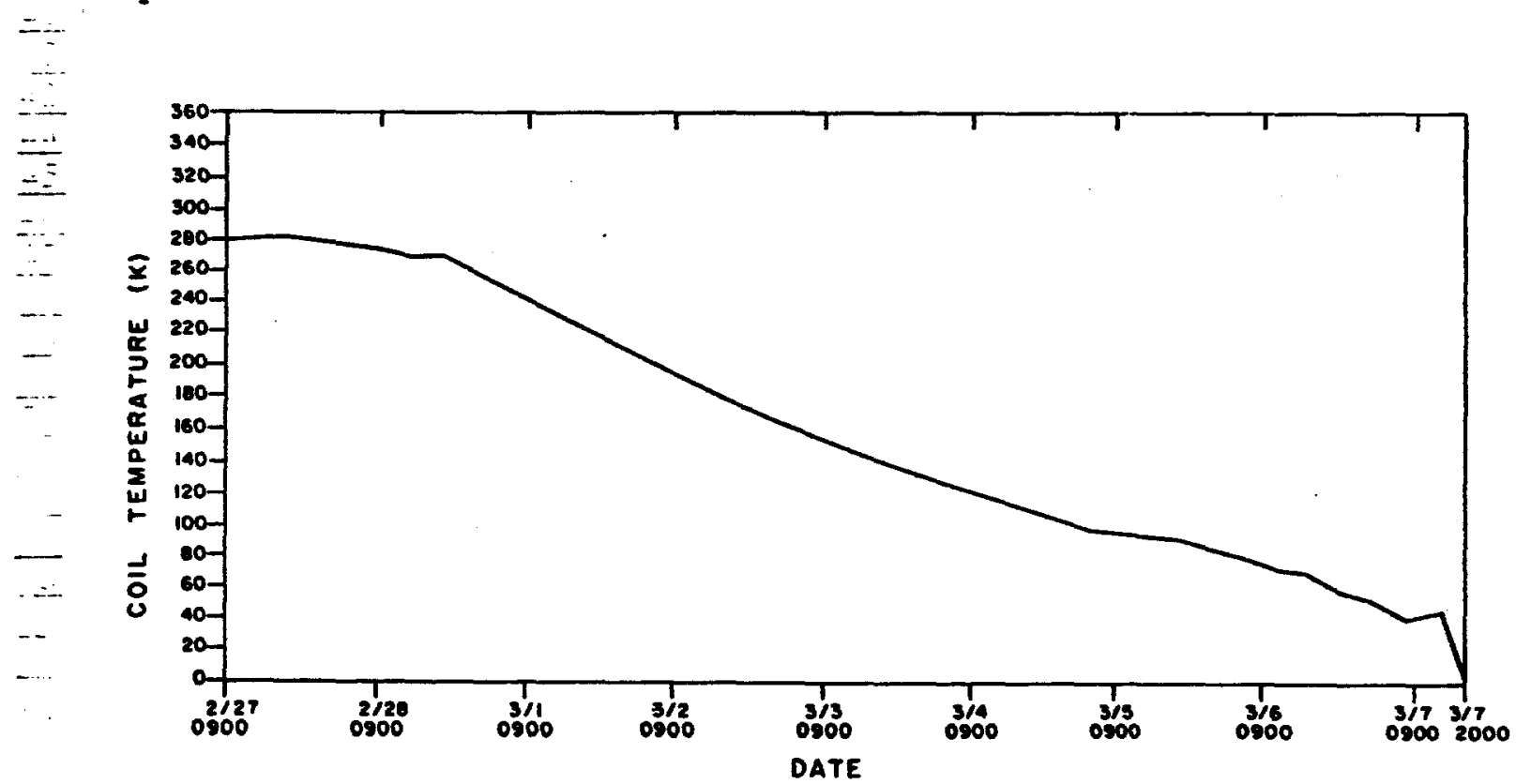

Fig. 3. Cooldown of magnet-refrigerator system. 
With the coll cold, W-2010 was completely closed to send all flow back through the refrigerator. Liquid began to accumulate in the storage dewar, and a liquid flow was established through the coll, f1111ng the control dewar. The atorage dewar was then f1lled to about one-half of Its 2000-L capac1ty, and the computer control loop enabled to maintain this 11quid level by regulating liquid expansion engine speed. The set point of the storage dewar pressure control loop was set to $0.04 \mathrm{MPa}$ (6 psig). The operation of EVCP, wh1ch regulated the control dewar pressure, was placed under computer control at a set point of $0.028 \mathrm{MPa}$ (4 p8ig). These pressures provided the differential for driving the magnet flow. The flow was also regulated by a control loop which monitored FIMP and adjusted EVMF accordingly. This flow was set at approximately $10 \mathrm{~g} / \mathrm{s}$ initially. The system was then stabilized under full computer control to await electrical testing.

Adjustment of supports. Special consideration was given during cooldown to the 24 radial support rods which suspend the coil within the vacuum shell. Th1s 18 a tension-only support system which relles on the thermal contraction of the coll and support rods during cooldown to provide a preload force. A titaniun alloy (6Al-4V) was used for the spherical bearing housings on the rod ends and, as this alloy exhlbits very low ductility and fracture toughness at cryogenic temperatures, it was necessary to monitor the rod stress closely and adjust the tension Individually If needed. To make this possible, the radial support system had been designed so that the room temperature end of each rod was attached to a tensioning device which penetrated the vacuum shell end rings through a double o-ring seal. This device contained a threaded shaft and nut. Adjusting this mut against the vacuum shell end ring applied tension to the support rod. Callbrated strain gauge washers installed under the nuts provided an accurate, computer monitored indication of rod tension.

The rods were designed for a maximum force of $7.9 \mathrm{Mg}$, corresponding to a total radial decentering force of $25.5 \mathrm{~kg}$. Because certain of the rods bear the cold mass of $\sim 5.6 \mathrm{Mg}$, the preload force varied from $4.8 \mathrm{Mg}$ to $5.8 \mathrm{Mg}$. The tensions were adjusted during cooldown to maintaln these desired values $\pm 1 \mathrm{Mg}$.

\section{Magnet Test Procedures and Basic Results}

A serles of tests at low current (100 to $1000 \mathrm{~A})$ were performed to verify proper operation of the interlock and quench protection systems and to callbrate and debug the Instrumentation. When this was complete the coll was energized to succeedingly higher currents in 5-MJ steps as shown In Table 3.

Table 3. Summary of Kagnet Test8

$\begin{array}{ccl}\begin{array}{c}\text { Current } \\ \text { (kA) }\end{array} & \begin{array}{c}\text { Stored } \\ \text { Bnerg } \\ \text { (M) }\end{array} & \begin{array}{c}\text { Tests } \\ \text { Performed }\end{array} \\ 1.0 & 1.2 & \text { FD, SD } \\ 1.5 & 2.7 & \text { FD, SD } \\ 2.0 & 4.8 & \text { FD } \\ 2.9 & 10.1 & \text { F. SD } \\ 3.5 & 14.7 & \text { H. FD } \\ 4.1 & 20.2 & \text { FD, H } \\ 4: 6 & 25.4 & \text { FD } \\ 5.0 & 30.0 & \text { FD, SD } \\ . \text { FD - Fast discharge (dump) } \\ \text { SD - Slow discharge (dump) } \\ \text { H - Heater tests }\end{array}$


The coll was typlcally charged wth the power aupply voltage regulating to give a linear ramp $\sim 250 \mathrm{~A} / \mathrm{min}$ over most of the charge. When the current in the coll was close to the desired value the power supply is switched to a current regulating mode which monitored a current transductor located on the coll bus. After the coll reached the current for each step, the magnet1c fleld in the bore, measured with a Hall probe, the electromagnet1c forces on the coll supports and the deflectlons of the yoke and end plug structures were recorded. Then fast dump was manually initlated. The coll voltages, temperatures and hellum c1rcult pressures resulting from the discharge were studied before proceeding to the next higher step in current. For some current values a slow dump was also manually Initlated. For currents less than $2 \mathrm{kA}$ it was deduced that the coil remain superconducting throughout the fast discharge since the observed time constant $(30.9$ 8) was in good agreement with that expected for a superconducting discharge, $T=L / R_{T}=2.4 \mathrm{H} / 0.076 \Omega=32 \mathrm{~s}$.

Above $\sim 3 \mathrm{kA}$, eddy currents flowing in the outer support cylinder caused the coll to quench during a fast discharge. In this case the coll resistance, In series with $R_{F}$, shortens the effective time constant of the discharge as shown. In Table 4, which also gives the maximum temperature reached in the center of the outer support cylinder after each fast discharge. The forces on the supports and deflections of the end wall and plug at $5 \mathrm{kA}$ are given In Table 5.

Keasured Stab1lity - Heater Test8

To study coll stability and quench propagation two heaters are Imbedded in holds in the outer support cylinder. One is located at the center of the coil while the other is near one end. Each heater consists of a small spool of resistance ribbon mounted 80 that it is in good thermal contact with the FRP layer on the outer diameter of the coll yet thermally isolated from the support cylinder. The heater simulates a release of mechanical energy at the support cylinder/FRP boundary. We were unable to quench the coll with $24-8,2.7-k J$ heater pulse at currents of 3.5 and $4.1 \mathrm{kA}$. The peak temperature of the outer support cylinder approximately $100 \mathrm{um}$ from the heater was $8.5 \mathrm{~K}$. The thermal time constant for the system to recover from such a temperature excursion was about one minute. An estimate of the energy balance between the ohnic heating of a section of normal conductor and the conduction cooling by the outer support cylinder gives an equilibrium temperature of $10 \mathrm{~K}$ for this magnet cur rent. It is possible that a small section of conductor beneath the heater does quench, but it recovers by conduction cooling if the magnet current

\section{Table 4. Fast Discharge Characterist1cs}

\begin{tabular}{|c|c|c|}
\hline $\begin{array}{l}\text { Current } \\
\text { (kA) }\end{array}$ & $\begin{array}{l}\text { Bffect Ive } \\
\text { time } \\
\text { constant } \\
\text { (s) }\end{array}$ & $\begin{array}{l}\text { Maximu } \\
\text { teaperature } \\
\text { (x) }\end{array}$ \\
\hline $\begin{array}{l}1.0 \\
1.5 \\
2.0 \\
2.9 \\
3.5 \\
4.1 \\
4.5 \\
5.0\end{array}$ & $\begin{array}{l}30.9 \\
30.9 \\
30.9 \\
29.4 \\
28.3 \\
27.0 \\
26.0 \\
19.5\end{array}$ & $\begin{array}{r}7 \\
8 \\
10 \\
21 \\
28 \\
34 \\
37 \\
45\end{array}$ \\
\hline
\end{tabular}




$\begin{array}{ll}\text { End Wall Deflection } & 2.5 \mathrm{~m} \\ \text { End Plug Deflection } & 5.0 \mathrm{~mm} \\ \text { Axilal Decentering Porce } & 27 \mathrm{Mg} \\ \text { Radial Decentering Force } & -1 \mathrm{Mg}\end{array}$

Is sufficlently low. Heater pulses of greater energy. were not applied due to concern about damaging the FRP Insulation. Heater tests were not attempted at higher excitations.

\section{Quench Behavior}

On four occassions during magnet testing and the two months of coll operation for magnetic fleld mapping and drift chamber testing, the coll quenched due to a rapld change of fleld and/or by inadequate flow of hellum. We belleve that we understand the observed quench behavior.

Quench $1-4.5 \mathrm{kA}$ quench whle charging. This quench occurred when rapidly charging the magnet $(390 \mathrm{~A} / \mathrm{mln})$ with a hellum flow rate of $13 \mathrm{~g} / \mathrm{s}$. The quench began in the end of the coll that has both axial and radial supports... Since. this end has the higher conduction heat load and since the hellum-temperature support intercepts lie at the end of the cooling circuit it is belleved that the liquid fraction was oufficiently low that the Intercepts were Ineffective, causing local hot spots at the support attachments. A plot of the observed voltages across each of the coil quadrants is shown in F1g. 4 for the few seconds before the time $(t=0)$ that the quench detection circuit activated the dump switches. From $t=$ -0.75 s to $t=0$, the voltage $\mathrm{VCl}=\mathrm{V} 3-\mathrm{V} 4$ increased by $0.34 \mathrm{~V}$ indicating a normal region growing in this quadrant. Similarly since the power supply voltage was maintained at a constant value, $\nabla C 2=\nabla 4-\nabla 5, \nabla C 3=\nabla 5-\nabla 6$

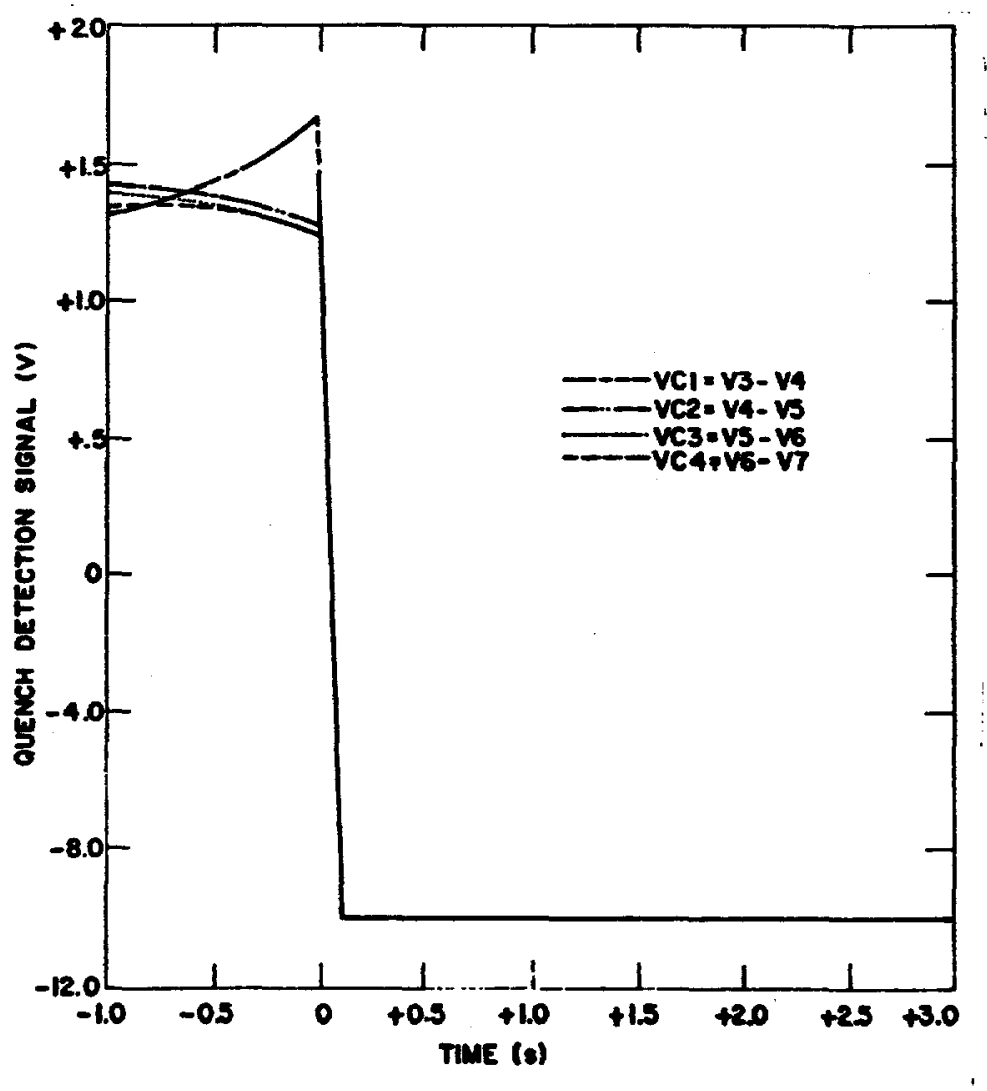

Fig. 4. Voltages observed across coll quadrants showing quench 
and VC4 = V6 - V7 all show a correspond1ng drop of $0.11 \mathrm{~V}$. Our instrunentation does not allow us to determine whether the dominant mode of quench propagation was axial from turn to turn or circumferentially along the conductor. (In the testing of a 1 m R\&D co1110 both modes were present.) However, if we assume that the propagation 18 purely circumferential we can estimate an effective circumferential quench velocity. In the 0.758 before $t=0$ the coll absorbs $15.2 \times 10^{6} A^{2}-8$ (15.2 MIITS). From the plot of maximum conductor temperature as a function of absorbed energy ${ }^{11}$ we concluded that the hot spot temperature at $t=0$ must have been $\sim 25 \mathrm{~K}$. The measured resistance of the coll per unit length of conductor is $0.17 \mu \Omega / m$ at $10 \mathrm{~K}$ and $\sim 0.3 \mu \Omega / \mathrm{w}$ at $25 \mathrm{~K}$. If we use a value of $0.23 \mathrm{\mu} \Omega / \mathrm{m}$ as the average conductor resistance in the $10-25 \mathrm{~K}$ region then a length of normal conductor of $324 \mathrm{~m} 18$ consistent with $\Delta V C 1$, giving an average circunferential quench velocity of $430 \mathrm{~m} / 8$.

The effective time constant for the quench was 268 which 18 in good agreement with that obtalned by fast dumping the coll. The 263 MIITS deposited Into the conductor during the discharge implied a hot opot temperature of $\simeq 67 \mathrm{~K}$.

After this quench the hellum flow rate was increased to $20 \mathrm{~g} / \mathrm{s}$ and no further quenches were observed during charging.

Quench $12-4.6 \mathrm{kA}$ quench during discharge. A quench also occurred following the manual initiation of a slow dump with the coll operating at $5 \mathrm{kA}$ with a $20 \mathrm{~g} / \mathrm{s}$ flow rate. Switch SWl was opened manually causing the coll to discharge through $R_{S}$ and $R_{B}$. The initial discharge rate was 650 A/min; the rate decayed exponentialiy with a time constant of $460 \mathrm{~B}$. Eddy current heating in the support cylinder caused a pressure rise in the control dewar which substantially reduced the hellum flow rate through the coollng circuit. Although the automatic control loop attempted to correct this condition by opening EVMF the response time was too slow and the coil quenched at $4.6 \mathrm{kA}$. The quench behavior was essentially 1dentical to that observed in quench 11. Slow dumps Inttlated at $4.6 \mathrm{kA}$ did not produce quenches. For the balance of this run the coll was discharged by turning down the current set point, wth the magnet current decaying through the power supply and free wheeling diode. When the magnet current reached $\sim 4 \mathrm{kA}$ a slow dump was inttlated. The long term solution is to reduce the value of the slow dump resistor to enable slow dumping from $5 \mathrm{kA}$ without quenches.

Quenches 3 \& 4 . Both of these quenches occurred due to control system errors during $5 \mathrm{kA}$ steady state operation. They were caused when itcroprocessor reboots commanded BVMF to close. When this happened the hellum flow Interlock started a slow dump. However, because of eddy current heating and no helluw flow, the coll quenched at $4.4 \mathrm{kA}$ and the quench protection system Initiated a fast dump.

Quench Recovery

All the quenches behaved similarly: The relief valves on the helium circult would typically open for 10-15 seconds expelling the 60-L cooling tube inventory and the control dewar pressure would reach $\sim 0.19 \mathrm{MPa}$ (27 psig). The recovery time to operating conditions was about 2 hours and was routinely performed by cryotechnicians.

\section{Preliminary Magnetic Fleld Mapping}

The magnetic field Inside the solenold was measured using three orthogonal search colls. The results of this measurement are described in detall elsewhere ${ }^{7}$; the axial fleld unfformity appears quite satisfactory. 
The successful test and firat operational run of the CDF refrigerator-magnet showed the system to be both safe and rellable. Modificat1ons are presently underway to permit slow dumping frow full excitation without a quench and to 1mprove the response of the refrigerator to quenches. The counters for the detector are now being 1nstalled around the magnet cryo8tat. The detector w1ll run for prellminary pp studies in the fall of 1985. For this run the magnet cannot be energ1zed because both the Tevatron and conventional accelerator beam plpes pass through the detector. The collider experimental program will commence in mid-1986 with all detectors and the magnet operational.

\section{ACKNOWLEDGYENTS}

The magnet-refrigerator portion of the CDF project was sponsored in part by the University of Trukuba under contract with the Japanese Ministry of Education and In part by Universities Research Association, Inc., under contract with the U. S. Department of Energy.

\section{REFERENCES}

1. R. Wands et al, IEEE Trans. In Magnet1c8 MAG-19:1368 (1983).

2. J. Grimson et al, In: "Proc. 12th Intl. Conf. on H1gh-Energy Accelerators," Permi National Accelerator Laboratory, Batavia, Illinois (1983), p. 639 .

3. H. Minemura et al, Nucl. Instrum. Methods 219:472 (1984) and Nucl. Instrum. Methods to be published (1985).

4. R. W. Fast et al, IEEE Trans. In Magnet1c8 MAG-21:963 (1985).

5. R. W. Past et al, 1n: "Proc. 10th Intl. Cryogenic Engineeing Conference," Butterworth, Gulldford, UR (1984), p. 78.

6. R. H. Wands and R. W. Fast, In: "Advances in Cryogenic Engineering," Vol. 29, Plenum, New York (1984), p. 377.

7. R. W. Fast et al, 1n: "Proc. 9th Intl. Conf, on Magnet Technology," Zurich (to be published).

8. M. G. Zabetak18, "Safety with Cryogenic Yluids," Plenum, New York (1967).

9. "Permilab Safety Manual," L. Coulson, ed., Ferml Mational Accelerator Laboratory, Batavia, I111nols (1981), chapter 15.1 .

10. S. Mori et al, in: “Advances in Cryogenic Engineering," Vol. 27, Plenum, New York (1982), p. 151.

11. R. W. Fast and A. D. McInturff, "CDF Design Note 69," Perml National Accelerator Laboratory, Batavia, Illinois, (1984) unpublished. 